\title{
12 Tips Jadi Pengusaha yang Tumbuh dan Sukses
}

\section{Ahadiyah Lailatul IImi}

Universitas Nahdlatul Ulama Sidoarjo ahadiyah@protonmail.com

Menjadi seorang wirausahawan yang tumbuh dan sukses berarti bahwa Anda sering merintis percobaan Anda sendiri, tidak memiliki panduan karier, konselor, atau peta yang akan memandu Anda dari satu langkah ke langkah lainnya mengada-ada saat Anda terus melangkah. Ada banyak banyak peluang yang tersedia bagi pengusaha untuk menciptakan dan menghasilkan uang dari ide bisnis mereka. Dengan peluang yang begitu besar, wirausahawan dengan mudah membuat kesalahan, kesalahan yang dilakukan oleh orang lain sebelum mereka.

Dunia dan masyarakat membutuhkan kewirausahaan (Setyawati, Purnomo, Irawan, Tamyiz, \& Sutiksno, 2018). Berikut adalah beberapa tips untuk memulai dan mengelola bisnis atau wirausaha anda. 


\section{Uraikan Apa Sebenarnya yang Diperlukan untuk Mencapai Tujuan Anda}

Sebagai seorang wirausahawan, Anda perlu mendefinisikan ide-ide yang akan membantu Anda dalam membuat bisnis sukses. Hanya Anda yang bisa mengendalikan dan tahu cara menghadapinya. Anda akan memiliki gagasan yang akan membantu bisnis Anda menjadi sukses tetapi hanya ketika Anda bereksperimen, Anda tahu mana yang berhasil dan yang tidak. Membangun kisah sukses Anda mengharuskan Anda menentukan terlebih dahulu apa yang berhasil (Wrights, 2016).

\section{Basis Bisnis Anda pada Keseimbangan Gairah dan Pengetahuan}

Membangun start-up dari awal, mungkin tampak mendapatkan prospek yang cerah, tetapi dalam kenyataannya, itu cukup menantang. Oleh karena itu, penting untuk sesuatu yang menggairahkan dan memotivasi Anda karena ini akan membuat minat dan investasi Anda tetap tinggi meskipun hal-hal tidak tampak terlalu bagus. Namun, mendasarkan usaha Anda semata-mata pada keberanian bukanlah langkah yang bijak karena banyak pengetahuan yang harus 
mendorong langkah Anda. Hindari bisnis atau industri yang belum Anda ketahui dengan baik karena kesalahan tertentu dapat meruntuhkan bisnis pemula Anda (Chakraborty, 2017). Wirausaha berbasis pendidikan dikenal sebagai edupreneur (Purnomo, 2017).

\section{Belajar dari Orang Lain}

Cukup sering pengusaha sukses telah bekerja untuk orang lain dalam bidang mereka sebelum mereka pergi sendiri. Bekerja selama beberapa tahun dengan mentor yang baik di industri dapat menawarkan landasan peluncuran yang bagus untuk memulai. Belajarlah dari kesalahan mentor Anda dan lakukan brainstorming tentang bagaimana model mereka dapat ditingkatkan. Temukan seseorang yang bersedia mengajari Anda, dan kemudian setelah Anda pergi, Anda dapat berpikir untuk memulai bisnis Anda sendiri (Reynolds, 2016).

\section{Arus Kas adalah Oksigen}

Tips dari Bill Aulet, direktur pelaksana Martin Trust Center for MIT Entrepreneurship di MIT dan dosen senior di MIT Sloan School of Management, yang darinya kami mendapat hak istimewa untuk belajar di Bootcamp 
Entrepreneurship MIT Entrepreneurship MIT. Dua tahun kemudian, baris yang kami tulis di catatan ini mengungkapkan kebenarannya. Anda benar-benar dapat membakar uang dengan cepat. Sebagai pengusaha bootstrap, ini terutama benar karena Anda tidak mampu melakukan kesalahan itu. Pastikan Anda sangat hemat dalam pengeluaran Anda. Hindari overhead kantor, konferensi yang terlalu mahal, dan hal-hal startup lainnya yang dapat dengan cepat bertambah. Usahakan agar barang-barang tetap setipis mungkin selama mungkin. Saran ini dapat membantu Anda bertahan cukup lama untuk menemukan kecocokan pasar-produk dan membangun perusahaan hebat yang akan mati jika tidak (Mérineau, 2017).

\section{Ketaatan kepada Tuhan}

Pemimpin wirausaha harus seperti IImu Nahwu dalam Bahasa Arab yaitu harus bisa Marfu' (dhummah) dan Manshub (fathah), jangan seperti Majrur dan Majzum. Marfu' yang berarti memeluk atau merangkul, sedangkan Manshub yang berarti terbuka tanpa ada yang ditutupi. Jangan seperti Majrur yang berarti menginjak-injak atau merendahkan orang lain. Seperti kata orang dahulu, yaitu Ngeluruk 
Tanpo Bolo, Menang Tanpo Ngasorake, Sakti Tanpo Aji-Aji, Sugeh Tanpo Bolo (Maula et al., 2017; Qori'ah et al., 2017). Setiap manusia yang memiliki ilmu termasuk ilmu wirausaha selayaknya harus mengamalkan ilmu tersebut (Asitah et al., 2017). Wirausaha senantiasa harus selalu berpegang teguh pada sifat yang dimiliki oleh Rasul yaitu jujur, amanah, fathana, siddiq selain itu juga harus bermodal ikhas, karena Allah ingin agamanya itu di amalkan, poin yang kedua yaitu do'a para alim dan ulama terdahulu lah yang sangat penting dan point yang ke tiga yaitu transparan kepada semua orang agar sesuatu yang di kerjakan mendapat kepercayaan dari orang lain (Munjidah, et al., 2017).

\section{Survei Audiens Anda untuk Mempelajari Apa yang Mereka Minati}

Fase paling penting adalah pekerjaan awal Anda: mensurvei audiens Anda untuk memahami apa yang paling mereka minati, dan kemudian menjalankan uji coba untuk menguji permintaan dan memastikan Anda memberikan informasi yang relevan dan penting bagi mereka. Itu akan menempatkan Anda pada jalur untuk menciptakan produk yang benarbenar diinginkan orang (Basu, 2018). 


\section{Kesempurnaan Sekrup}

Jika Anda seorang perfeksionis, bersiaplah untuk terapi kejut (kami salah satunya!). Saat Anda berada di perusahaan, Anda memiliki waktu dan sumber daya untuk menyempurnakannya (atau hampir sempurna). Ketika Anda seorang pengusaha, Anda tidak lagi memiliki kemewahan itu.Kecepatan mengalahkan kesempurnaan setiap hari. Jadi, inilah satu tip yang berguna untuk Anda: cukup baik cukup baik untuk dikirim. Jika Anda tidak membangun, Anda tidak belajar. Keindahannya adalah Anda akan segera menyadari betapa tidak sempurna asumsi Anda untuk memulai (Mérineau, 2017).

\section{Tanyakan pada Diri Sendiri Siapa yang Anda Butuhkan untuk Mendapatkan Hasilnya}

Untuk segala hal baik atau buruk dalam hidup Anda, Anda adalah penyebut yang sama. Kehebatan berasal dari pemahaman bahwa siapa diri Anda mengubah keefektifan dari apa yang Anda lakukan (Meis, 2017). 


\section{Bangun Platform Pribadi Anda tetapi Jangan Mencoba Menarik bagi Semua Orang}

Anda tidak harus menarik setiap orang, tetapi jika ada seseorang atau sekelompok kecil orang yang benar-benar percaya pada konten yang Anda bagikan dan mereka menemukan nilai di dalamnya, jika Anda benarbenar melayani aspirasi yang mereka memiliki, maka mereka akan membagikannya dengan orang lain, mereka akan menjadikan itu bagian dari hidup mereka. Dan pada akhirnya, memiliki platform pribadi memungkinkan Anda untuk mencapai tidak hanya hal-hal yang Anda inginkan untuk diri sendiri dan keluarga Anda tetapi pada akhirnya warisan yang ingin Anda tinggalkan di dunia ini (Basu, 2018).

\section{Jangan Multitask}

Hari-harimu entah kenapa sibuk. Namun, jika memungkinkan, hindari multitasking dan asah fokus Anda pada pekerjaan yang sedang dihadapi. Ketika Anda ditarik dalam seratus arah setiap hari, mudah untuk bangkit dari tugas ke tugas. Namun, ini tidak efisien - pekerjaan dibiarkan terbuka dan tidak lengkap, atau kesalahan dilakukan karena pengawasan yang sederhana. Tetap fokus 
pada satu tugas sampai selesai memastikan bahwa mereka dikecualikan dan dilakukan untuk potensi penuh (DiScala, 2017).

\section{Belajarlah untuk Melakukan Inovasi Terbuka}

Mari kita buat hidup lebih sederhana untuk diri kita sendiri dan tidak menemukan kembali roda. Ini adalah tujuan penting dari inovasi terbuka. Ini hanya berarti menyatukan pengetahuan yang ada dan bukannya terusmenerus menciptakannya kembali dari awal. Pengetahuan apa yang ingin Anda integrasikan ke perusahaan Anda?. Informasi apa yang ingin Anda bagikan? (L'Écuyer, 2016).

\section{Mulai Sekarang}

Penting untuk merencanakan berbagai hal sebelum memulai bisnis. Hal yang sama berlaku bahwa Anda tidak akan pernah menjadi wirausahawan sejati sampai Anda mewujudkan ide Anda dan mengujinya. Jangan mengambil banyak waktu perencanaan dan lupa menguji ide itu. Buat konsep rencana aksi dan kerjakan. Uji rencana dengan teman, kerabat, atau kolega Anda dan kenali pendapat mereka tentang bisnis tersebut (Kleim, 2018). 


\section{References}

Asitah, N., Usmawati, D.Z., Rosyidah, E., \& Purnomo, A. (2017). MI Hasyim Asy'ari IImu Harus Terus Mengarus. In

Wirausaha Pendidikan Indonesia (Jilid 2). Sidoarjo: Unusida Press.

Basu, T. (2018). Top 20 Tips for Building a Business from Successful Entrepreneurs. Retrieved May 17, 2019, from https://www.thinkific.com/blog/tipsbuilding-a-business-successfulentrepreneurs/

Chakraborty, R. (2017). \#7 Best Tips for Firsttime Entrepreneurs. Retrieved June 1, 2019, from https://www.entrepreneur.com/article/2989 01

DiScala, J. (2017). 8 Essential Productivity Tips for the Busy Entrepreneur. Retrieved May 21, 2019, from https://www.inc.com/john-discala/8essential-productivity-tips-for-busyentrepreneur.html

Kleim, M. (2018). Top 10 Tips For First-Time Entrepreneurs Willing To Be Successful. Retrieved May 26, 2019, from https://small-bizsense.com/10-tips-for- 
first-time-entrepreneurs/

L'Écuyer, J.-P. (2016). Ten Tips to Becoming a Better Entrepreneur. Retrieved May 25, 2019, from

https://www.futurpreneur.ca/en/2016/tentips-to-becoming-a-better-entrepreneur/

Maula, I., Mufidah, F.I., Rosyidah, E., \& Purnomo, A. (2017). SD Antawirya Islamic Javanese School Mother is Culture. In Wirausaha Pendidikan Indonesia (Jilid 1). Sidoarjo: Unusida Press.

Meis, C. (2017). 7 Tips for the Struggling Entrepreneur. Retrieved June 7, 2019, from https://www.success.com/7-tips-forthe-struggling-entrepreneur/

Mérineau, É. (2017). 17 tips for first-time entrepreneurs in 2017. Retrieved May 20, 2019, from https://medium.com/@etiennemerineau/1 7-tips-for-first-time-entrepreneurs-in-2017e98cda59aa41

Munjidah, A, Zannah, I.P.N., Purnomo, A., Rosyidah, E. (2017). MI Thoriqussalam Berpegang Kepada Rosul. In Wirausaha Pendidikan Indonesia (Jilid 4). Sidoarjo: Unusida Press. 
Purnomo, A. (2017). Pengertian Edupreneur. https://doi.org/10.31227/osf.io/8fnu6

Qori'ah, S., Sholikhah, S.A., Purnomo, A., \& Rosyidah, E. (2017). MI Progresif Bumi Sholawat dengan Kebenaran Semua Pasti Ada Jalan. In Wirausaha Pendidikan Indonesia (Jilid 3). Sidoarjo: Unusida Press.

Reynolds, C. (2016). 8 Tips For Becoming a Successful Entrepreneur. Retrieved June 2, 2019, from

https://www.business2community.com/str ategy/8-tips-becoming-successfulentrepreneur-01567069

Setyawati, I., Purnomo, A., Irawan, D. E., Tamyiz, M., \& Sutiksno, D. U. (2018). A Visual Trend of Literature on Ecopreneurship Research Overviewed within The Last two Decades. Journal of Entrepreneurship Education, 21(4), 1-7. Retrieved from https://www.abacademies.org/articles/avisual-trend-of-literature-onecopreneurship-research-overviewedwithin-the-last-two-decades-7468.html 
Wrights, J. (2016). 5 Tips on Becoming a

Successful Entrepreneur-Tactics That

Can Help Your Business Grow. Retrieved

May 10, 2019, from

https://www.entrepreneur.com/article/2814

90 